\title{
STANDAARDE VIR DIE INTERHOSPITAALVERVOER VAN SIEK NEONATE
}

\author{
M.E. Muller, A.G.W. Nolte, J.C. Roux
}

\section{INLEIDING}

Teen die middel van die sewentiger jare het gevorderde tegnologie en goed opgeleide gesondheidspersoneel verbeterde nageboortesorg vir hoë risiko neonate verseker (10: 2). Die koste van gesofistikeerde neonatale sorg bemoeilik die lewering van hierdie tipe dienste in alle hospitale. Babas wat dus ná geboorte siek word by sentra waar hierdie dienste nie beskikbaar is nie, moet na die groter sentra vervoer word. Die standaard van interhospitaalvervoer van siek neonate is derhalwe ' $n$ bepalende faktor in die mortaliteit van hierdie neonate.

Verskeie outeurs is dit eens dat swak of onvoldoende toerusting ' $n$ belangrike rol speel in die verswakking van 'n neonaat se toestand tydens vervoer $(10: 4-5 ; 6: 53-54$; 20: 48). Bo-en-behalwe die standaard van toerusting in die ambulans, speel die kundigheid en vaardighede van die vervoerpersoneel ook ' $n$ kardinale rol (8: 42). Daarbenewens is kommunikasie 'n kern faktor. Dit sluit die kommunikasie tussen die verwysende geneesheer en die ambulanspersoneel in, asook die

kommunikasie van die ambulanspersoneel onderling en tussen die ambulanspersoneel en die personeel van die sentrum wat die neonaat gaan ontvang (20:40-49).

Dit is derhalwe belangrik dat 'n siek neonaat onder optimale omstandighede vervoer word. 'n Gebrek aan standaarde in hierdie verband, bemoeilik die evaluering van gehalte interhospitaalvervoer van siek neonate. Daar bestaan dus 'n dringende behoefte aan standaarde vir die interhospitaalvervoer van siek neonate.

Die doel van hierdie ondersoek is om geldige standaarde vir die interhospitaalvervoer van siek neonate te formuleer waarvolgens die gehalte van hierdie dienslewering beoordeel kan word.

\section{LITERATUUROORSIG}

Daar is verskeie faktore wat die effektiewe interhospitaalvervoer van siek neonate beïnvloed. Hierdie faktore sentreer rondom die ambulansvoertuig, toerusting en voorrade, die vervoerpersoneel en kommunikasie.

\section{Ambulansvoertuig}

'n Ambulans is ' $n$ voertuig wat toegerus is om siekes en beseerdes te vervoer (21: 55 ). Ten einde ' $n$ effektiewe nooddiens te kan lewer moet die ambulans aan verskeie ander vereistes voldoen. Die ambulansvervoer verteenwoordig die voortsetting

\section{Uittreksel}

Die vervoer van siek neonate tussen hospitale en/of gesondheidsdienssentra, speel 'n belangrike rol in die mortaliteitsyfer van hierdie ernstige siek neonate. Dit is belangrik dat 'n siek neonaat onder optimale omstandighede vervoer word. 'n Gebrek aan standaarde in hierdie verband bemoeilik die evaluering van gehalte interhospitaalvervoer van siek neonate. Die doel van hierdie studie is om geldige standaarde vir die vervoer van ernstige siek neonate tussen die hospitale (en/of ander gesondheidsdiens-sentra) te formuleer waarvolgens die gehalte van hierdie dienslewering beoordeel kan word. Faktore wat 'n rol speel sentreer rondom die ambulansvoertuig. toerusting en voorrade, die vervoerpersoneel en kommunikasie. Hierdie faktore is sistematies verken en in die vorm van standaarde beskryf en geformuleer.

\section{Abstract}

The transport of ill neonates between hospirals and/or health care centres, plays an important role in the mortality rate of these seriously ill neonates. It is therefore important that the ill neonate is transported under optimal

conditions. A lack of standards in this regard hampers the evaluation of the quality of inter hospital transport of ill neonates. The purpose of this study is to formulate valid standards for the transport of seriously ill neonates between hospitals (and/or other health care institutions) to form the basis for the evaluation of the quality of this service. Factors that need to be considered in the transport of ill neonates include the ambulance, equipment and stock, the transport personnel and communication. These factors were systematically explored and described and standards were formulated accordingly.

van nood-mediese sorg.

Die ambulansdiens behoort op ' $n$ vieren-twintig uur basis beskikbaar te wees (12: 469). Die ruimte en beligting behoort toereikend te wees met 'n bestuurderskompartement, asook 'n kompartement wat 'n pasiënt en twee ambulanspersoneellede kan akkommodeer. Genoegsame beligting binne die ambulans moet beskikbaar wees ten einde akkurate observasie en veilige lewering van noodsorg moontlik te maak (1:337; 20 : 32-34).

Krag- en suurstofvoorsiening is kardinaal vir die neonaat se noodsorg. Daar moet ' $n$ addisionele suurstofbron beskikbaar wees in die ambulans buiten die vervoerbare suurstof wat saam met die vervoerbroeikas gebruik word (20: 32-34).

Daar moet in die ambulans ' $n$ kommunikasiestelsel wees waarmee die hospitaal, waarna die neonaat verwys is, en die voertuig met mekaar in verbinding kan bly. Hierdie kommunikasiestelsel moet oor groot afstand kan funksioneer (12: 469; 20: 32-34).

Dit is voorts nodig dat die ambulans, volgens 'n gekontroleerde skedule, werktuigkundige diens ontvang om probleme, tydens die vervoer van neonate, tot die minimum te beperk. Die American Academy of Orthopaedic Surgeons (1: 343 344 ) is van mening dat 'n volledige werktuigkundige diens na elke 1600 kilometer, nodig is.

\section{Toerusting en voorrade}

Die voorkoming van suurstofdeprevasie, blootstelling aan koue en gevolglike hipoglisemie, apnee en sianose van die neonaat, is van die kritieke faktore wat 'n rol speel in die ontwikkeling van veilige vervoermetodes vir neonate $(11: 205 ; 13$ : 31). Volgens Frantz (12: 469) behoort die toerusting in die ambulans die vervoerspan in staat te stel om as 'n vervoerbare neonatale eenheid te kan funksioneer.

Die vervoerbroeikas is sekerlik die belangrikste toerusting vir die vervoer van neonate om die optimale

liggaamstemperatuur te handhaaf ten einde metaboliese- en suurstofsteurings by die siek neonaat te voorkom (18: 260). Die toestand van ' $n$ neonaat wat van een sentrum na ' $n$ ander vervoer word, is reeds sodanig verswak dat die addisionele stres van hipo- en hipertermie vir hierdie neonaat fataal kan wees. Deursigtigheid van die broeikas om observasies en hantering van neonaat te vergemaklik, is ook belangrik. Die suurstof- en kragbron, asook die hanteerbaarheid van die broeikas, is ook bepalende faktore. Die standaard van die vervoerbroeikas, wat immobilisering van die broeikas insluit, is dus belangrik om aan hierdie optimale vervoervereistes te kan voldoen (2: 945; 5 : 12; 19: 235). 
Die beskikbaarheid van 'n suurstofanaliseerder verminder die risiko van te veel of te min suurst oftoediening aan die siek neonaat en word as 'n belangrike apparaat in die ambulans beskou (4: 571 ).

Die instandhouding en monitering van liggaamsregulerende meganismes by die siek neonaat vereis ook die beskikbaarheid van 'n kardio-respiratoriese monitor, ' $n$ neonatale ventilator, 'n suigapparaat en 'n elektroniese infuuspomp $(3: 148 ; 6: 56 ; 12$ : 471). Die effektiewe resussitering van die neonaat moet dus moontlik wees.

Buiten die beskikbaarheid van die voorafgaande gesofistikeerde toerusting is ander, maar nie minder belangrike, resussiteringstoerusting en -voorraad ook 'n vereiste. Lugweë, endotracheale buise (vir neonate), 'n laringoskoop met bykomstighede, asook die neonatale ambusak, is standaard toerusting vir ' $n$ ambulans om die vervoer van die neonate te beveilig. Die hantering van nood pleurale dreinering vereis die beskikbaarheid van 'n Heimlich borskasdreineringsklep en gepaardgaande trokarapparaat $(6: 57 ; 19: 236)$.

Die handhawing van die neonaat se vogen elektrolietbalans vereis verder die beskikbaarheid van intra-veneuse toerusting en voorrade (20:38). Toerusting vir die monitering van die neonaat se vitale tekens, soos 'n stetoskoop, termometer en apparaat vir die bepaling van glukose, word deur Cannon (6: 38) as 'n vereiste gestel.

Die ambulans kan voorts nie sonder noodmedikasie 'n neonaat veilig vervoer nie. Die kommunikasiestelsel behoort die voorskryf van medikasie te vergemaklik. Die beskikbaarheid van items soos adrenalien, dekstrose, asemhalingstimulante, ensovoorts, word as essensiee beskou.

\section{Vervoerpersoneel}

Die vervoerspan behoort saamgestel te word uit twee individue wat ondervinding van neonatale sorg het en wat bevoeg is om besluite te neem met betrekking tot die hantering van die neonaat, en om prosedures, soos intubering, resussitering, en inwerkingstelling van 'n infuus, te kan uitvoer.

Volgens Clarke (8: 42) en Cannon (6: 54) is een van die grooste risikos van neonatale vervoer, die blootstelling aan onvoldoende opgeleide personeel. Die veilige en optimale vervoer van siek neonate vereis neonatale spesialiste, geneeskundig en verpleegkundig, wat oor die nodige vaardighede beskik. 'n Studie deur Chance, Matthew \& Cash (7: 662-666) het bewys dat siek neonate, wat tydens die vervoer deur gespesialiseerde en vaardige vervoerspanlede versorg is, opgeneem is met noemenswaardige hoër temperature, beter suurbasisewewig en 'n laer insidensie van respiratoriese nood. Hierdie neonate het ook 'n laer mortaliteit getoon en hul hospitaalverblyf was korter as dië van die ander groep neonate.

Die lede van die vervoerspan behoort oor tegniese vaardighede te beskik wat tracheale intubering, inwerkingstelling van intra-veneuse infusie, dreinering van 'n pneumotoraks, resussitering van die neonaat, en die inplasing van 'n umbilikale kateter, insluit. Dit is verder ook noodsaaklik dat die vervoerpersoneel bekend sal wees met die toedieningsroetes en newe-effekte van die noodmedikasie wat hulle gebruik (9: 37; 12: 469).

Die verantwoordelikhede van die ambulanspersoneel sluit verder die stabilisering van die neonaat in, te wete die handhawing van 'n normale temperatuur, 'n arteriële suurstofvlak wat nie breinskade kan veroorsaak nie, ' $\mathrm{pH}$ wat nie asidoties is nie, 'n hematokrit en bloedvolume wat goeie weefselperfusie toelaat, 'n normale vloeistofstatus, asook geen metaboliese afwykings soos hipoglisemie of hipokalsemie nie $(5: 5,8: 42)$.

Nadat aan die voorafgaande vereistes voldoen is, kan die ambulansrit relatief stadig en veilig verloop. As noodprosedures uitgevoer moet word, moet dit nie in die bewegende voertuig gedoen word nie, maar moet die voertuig stilhou. Dit is belangrik om vinnig by die neonatale intensiewe sorgeenheid te kom, maar veiligheid bly die grootste oorweging (6: 54).

\section{Kommunikasie}

Goeie kommunikasie tussen al die leweraars van neonatale sorg tydens die hele vervoerproses is essensieel om die sukses van die rit te verseker. Hierdie kommunikasie sluit pre-, tydens-en postvervoerkommunikasie in. In die prevervoerkommunikasie tref die verwysende mediese praktisyn die nodige pre-vervoerreëlings en gee toepaslike inligting aan die vervoerpersoneel aangaande spesiale voorbereidings wat nodig mag wees ten einde die neonaat effektief te kan vervoer. Die neonatale intensiewe sorgeenheid wat die neonaat gaan ontvang, moet ook die nodige voorbereidingsinligting ontvang. Die graad van erns betreffende die neonaat se siekte-toestand, asook 'n beraamde aankomstyd, is belangrike inligting. Alle skriftelike verslae en dokumentasie van die neonaat, moet ingesluit word (15: 385; 17: 139).

Tydens vervoer speel rekordhouding die grootste rol in die kommunikasieproses. Gedetaileerde rekordhouding van observasie tydens die vervoer is belangrik. 'n Gestandaardiseerde dokumentasiestelsel, wat deur pediaters goedgekeur is, sal die rekordhouding vergemaklik $(5 ; 16 ; 15$ : 386). Kommunikasie met die mediese praktisyn vir die gee/aanbeveling van voorskrifte tydens die rit, is ook belangrik.

Om die effektiwiteit van die vervoersisteem te evalueer is 'n koördineringskomitee, bestaande uit ambulanspersoneel, mediese praktisyns, verpleegkundiges en ander tersaaklik gesondheidspersoneel, nodig. Die beoordeling van interhospitaalvervoer van siek neonate behoort dus op 'n gereelde basis deur hierdie komitee bespreek en beoordeel te word (5: 16).

Kommunikasie tussen vervoerpersoneel en die neonaat se ouers word deur Ingalls \& Salerno (14: 284) as belangrik beskou.
Voordat die vervoerspan die hospitaal verlaat, is die gee van volledige inligting aan die ouers, betreffende die toestand van die neonaat, die rede vir oorplasing, die bestemming van die neonaat, ensovoorts, belangrik.

Gehalte dienslewering in die vervoer van neonate is dus afhanklik van 'n goed toegeruste ambulansdiens, kundige en vaardige vervoerpersoneel, en 'n effektiewe kommunikasiestelsel. Dit is die voortsetting van 'n neonatale intensiewe sorgeenheid om die mortaliteitsyfer van siek neonate, wat interhospitaalvervoer benodig, te verminder.

\section{DEFINIERING VAN TERME \\ Neonaat}

'n Baba word vanaf geboorte tot 'n ouderdom van vier weke of agt-en-twintig dae as ' $n$ neonaat bestempel.

\section{Interhospitaalvervoer}

Dit is die vervoer van 'n pasiënt vanaf een gesondheidsdiens/hospitaal na 'n ander hospitaal, vir die doel van hierdie ondersoek, per padambulans.

\section{Standaard}

'n Standaard is 'n beskrywende verklaring van die verwagte vlak van werkverrigting waarteen die gehalte van dienslewering beoordeel kan word.

\section{NAVORSINGSMETODE}

Ten einde teoretiese geldigheid vir die formulering van standaarde vir die interhospitaalvervoer van siek neonate te verseker, is 'n grondige literatuurstudie in hierdie verband onderneem. Amerikaanse, Britse, Nederlandse en Australiese literatuur is hoofsaaklik gebruik, aangesien minimale literatuur in die Suid-Afrikaanse konteks in hierdie verband bestaan. Die domeinveranderlikes is sistematies verken, beskryf en gevalideer.

Oordeelkundige steekproefneming is vanuit 'n teikenpopulasie in die Johannesburgse area vir die validering van die standaarde gebruik. Lynn (16: 383) beveel 'n minimum van vyf domeinkundiges vir die validering van standaarde aan.

Die volgende domeinkundiges is geselekteer:

- 'n bekende pediater in privaatpraktyk;

- 'n pediater verbonde aan 'n provinsiale hospitaal;

- twee geregistreerde verpleegkundiges wat oor gespesialiseerde na-basiese $\mathrm{kwalifikasies}$ in neonatologie beskik en in bevel van neonatale intensiewe sorgeenhede, (in 'n provinsiale- en privaathospitaal in Johannesburg), is;

- 'n geneesheer wat aan die hoof van die opleiding van ambulanspersoneel in Johannesburg staan;

- 'n Verloskunde lektrise in Johannesburg.

Konsepstandaarde is vir bespreking voorberei en aan hierdie groep kundiges voorgelê. Die doel van hierdie bespreking 
was om die standaarde te verfyn, verder te ontwikkel of uit te brei ten einde die inhoudsgeldigheid van die standaarde te bekragtig. Die toepaslikheid, volledigheid en duidelike formulering van die standaarde is bespreek. Geringe veranderinge is aangebring en die finale standaarde is opgestel en finaal deur die groep gevalideer. Die inhoudsgeldigheid van die standaarde is dus deur die literatuur en domeinkundiges bevestig.

\section{RESULTATE}

Die volgende standaarde is geformuleer:

\section{Produkstandaard}

Die neonaat word veilig en doeltreffend vervoer.

\section{Struktuur- en proses-standaarde}

1. Kommunikasie tussen lede van die vervoerspan vind effektief plaas:

- Pre-vervoer-reëlings word deur die verwysende geneesheer getref.

- Die verwysende geneesheer gee toepaslike inligting, aangaande spesiale voorbereidings nodig vir die vervoer van die neonaat, aan die ambulanspersoneel.

- Die ambulanspersoneel telefoneer die toepaslike neonatale eenheid en gee inligting in verband met die neonaat se huidige toestand.

- Die ambulanspersoneel gee tersaaklike voorbereidingsinligting aan die neonatale eenheid se personeel.

- 'n Kommunikasiestelsel tussen die ambulanspersoneel en die geneesheer is teenwoordig.

- 'n Koördineringskomitee, wat saamgestel is uit ambulanspersoneel en tersaaklike gesondheidspersoneel, bestaan.

- Die koördineringskomitee vergader ten minste een maal per maand (of volgens behoefte en die frekwensie van vervoer wat plaasvind) om vervoerprobleme te bespreek.

- Skriftelike dokumentasie ten opsigte van vervoerreëlings tussen die geneesheer en ambulanspersoneel word gehou.

- Volledige skriftelike rekord word gehou ten opsigte van die volgende:

- naam van neonaat

- moederlike geskiedenis

- bevallingsbesonderhede

- vitale tekens van neonaat voor vervoer

- vitale tekens van neonaat tydens vervoer

- behandeling van neonaat voor vervoer

- behandeling van neonaat tydens vervoer.

- Ambulanspersoneel maak seker dat die volgende dokumente die neonaat vergesel:

- fotokopieë van al die neonaat se bedkaarte

- alle X-strale van die neonaat

- alle laboratoriumsversale van die neonaat
- 'n toestemmingsvorm vir die vervoer van die neonaat en behandeling by die hospitaal wat die neonaat ontvang (deur die ouers of tersaaklike verantwoordelike persoon geteken). Kommunikasie tussen die vervoerspan en die ouers van die neonaat vind effektief plaas:

- Die vervoerspan wys die neonaat vir die ouers voor hulle vertrek.

- Die vervoerspan gee aan die ouers inligting oor waarheen hulle neonaat vervoer word.

- Die vervoerspan beantwoord vrae wat die ouers stel.

- Die vervoerspan gee verskaf aan die ouers die nodige inligting (byvoorbeeld ' $n$ inligtingstuk) rakende die neonatale eenheid.

- Die vervoerspan kontak die ouers met aankoms by die neonatale eenheid en gee tersaaklike inligting.

Die vervoermiddel (ambulans) is effektief toegerus.

- Die diens is vier-en-twintig uur beskikbaar.

- Die diens is sodanig toegerus om op twee oproepe gelyktydig te kan reageer.

- Die ambulans beskik oor 'n addisionele suurstofvoorraad (byvoorbeeld 'n silinder) buiten dié van die broeikas.

- Die ambulans beskik oor 'n addisionele 12 volt kragbron wat onafhanklik is van die batterye aan die toerusting.

- Die ambulans voorsien in voldoende sitplek vir die betrokke personeel.

- Die ambulans voorsien in voldoende ruimte vir die veilige hantering van die neonaat.

- Daar is voldoende beligting in die ambulans om observasie van die neonaat moontlik te maak.

- Alle toerusting het 'n selfstandige en vervoerbare kragbron.

4. Die vervoerbroeikas maak optimale hantering en observasie van die neonaat moontlik.

- Die broeikas kan aan die ambulans vasgemaak word om dit te immobiliseer.

- Die broeikas kan 'n konstante temperatuur van $36^{\circ} \mathrm{C}$ handhaaf.

- Luike wat kan toemaak is teenwoordig waardeur die neonaat hanteer kan word.

- Die neonaat is maklik en duidelik sigbaar.

- Suurstof kan direk aan die broeikas gekoppel word vir toediening.

- Die broeikas het ekstra openinge waardeur buise ingelaat kan word.

- Die broeikas word minstens jaarliks gediens.

5. 'n Toereikende suurstofbron is teenwoordig.

- Die suurstofbron is vervoerbaar (byvoorbeeld 'n silinder).

- Die suurstofbron beskik oor 'n standaard vloeimeter wat tot 15 liter suurstof per minuut kan lewer.

- Die suurstof verseker voldoende suurstof vir twee maal die verwagte duur van die reis.

- 'n Suurstofanaliseerder is beskikbaar.

6. 'n Kardio-respiratoriese monitor is beskikbaar.

- Die monitor is in werkende toestand.

- Die nodige bykomstighede is beskikbaar.

7. 'n Veelsydige baba-ventilator is beskikbaar.

- Die ventilator lewer positiewe eindekspiratoriese druk.

- Die ventilator kan voortgesette positiewe lugwegdruk lewer tydens spontane asemhaling.

- Die ventilator word jaarliks gediens.

8. 'n Intra-veneuse infusiepomp geskik vir neonate is beskikbaar.

- Die infusiepomp meet en dien klein hoeveelhede vloeist of akkuraat toe.

- Die infusiepomp word jaarliks gediens.

9. Resussitasie-toerusting met toepaslike bykomstighede/voorrade is beskikbaar en in werkende toestand:

- 'n Suigapparaat

- Intubasietoerusting (laringoskoop en -lemme, stilet, endotrageale buise, batterye, gloeilampies vir laringoskoop)

- Toerusting vir pleurale dreinering (Heimlich klep)

- Toerusting vir die bepaling van vitale tekens

- Toerusting/voorraad vir die inwerkingstelling van ' $n$ intraveneuse infuus (infuusnaalde, oorgietingstelle, pleisters, alkoholdeppers en oorgietingsvloeistof)

- Neonatale resussitering/ambusak

- Apparaat/toerusting vir die bepaling van bloedglukose (byvoorbeeld desktrostix)

- Noodmedikasie.

10. Daar is voldoende effektief opgeleide vervoerpersoneel om 'n neonaat veilig te kan vervoer.

- Twee ander persone buiten die bestuurder is beskikbaar.

- Indiensopleiding in verband met die hantering van neonate word gegee

- Die vervoerpersoneel lewer bewys van die volgende vaardighede:

- resussitering van die neonaat

- intubering van die neonaat

- inwerkingstelling van ' $n$ intraveneuse infuus

- noodbehandeling van ' $\mathrm{n}$ spanningspneumotoraks.

- Vervoerpersoneel beskik oor die volgende kennis:

- toedieningsroetes van noodmedikasie

- effekte en newe-effekte van noodmedikasie

- beginsels van noodbehandeling van siek neonate.

\section{GEVOLGTREKKINGS EN \\ AANBEVELINGS}

Hierdie standaarde kan as riglyn dien vir die beoorderling van die gehalte interhospitaalvervoer van siek neonate. Dit het ook 'n gebruiksnut as 'n selfevaluerings- 
instrument vir beide openbare- en privaatambulansdienste om sodoende die algehele gehalte vir interhospitaalvervoer van siek neonate landwyd te verbeter.

Nasionale validering van die standaarde word aanbeveel waartydens die geldigheid van die standaarde ook statisties verreken word.

\section{BRONVERWYSINGS}

1. American Academy of Orthopaedic Surgeons. 1981. Emergency care and transportation of the sick and injured. Chicago: George Banta.

2. American Academy of Pediatrics. 1986. Committee on hospital care: guidelines for air and ground transportation of pediatric patients. Pediatrics, 5 (78), November, 943-949.

3. Bacon, C. 1983. Paediatric emergencies. A housemans' pocketbook. London: William Heineman.

4. Berk, J.L., Sampliner, J.E. 1982. Handbook of critical care. Second edition. Boston: Little Brown.

5. Bowen, P.A. 1980. Regional centers: part II: the newborn transport system. Issues in health care of woman, 5-6(2), SeptemberDecember, 5-17.

6. Cannon, J.A. 1983. Neonatal transport (In Avery, G.B. ed.: Neonatology: Pathophysiology and management of the newborn). Philadelphia: JB Lippincott.
7. Chance, G.W., Matthew, J.D., Cash, J. 1978. Neonatal transport: a controlled study of skilled assistance. Journal of Pediatrics, 15(93), 662-666.

8. Clarke, T.A. 1985. A review of neonatal transports. Irish Medical Journal, 2(78), February, 40-43.

9. Crosse, V.M. 1975. The preterm baby and other babies with low birth-weight. New York: Churchill Livingstone.

10. Evans, H.E., Glass, L. 1977. Perinatal medicine. New York: Harper and Row.

11. Field, P. 1984. Perinatal nursing. New York: Churchill Livingstone.

12. Frantz, I.D. 1985. Infant transport. Toronto: Little Brown.

13. Harper, R.G., Yoon, J.J. 1974. Handbook of neonatology. Chicago: Year Book Medical Publishers.

14. Ingalls, A.J., Salerno, M.C. 1983. Maternal and child health nursing. Toronto: $\mathrm{CV}$ Mosby.

15. Klaus, M.H., Fanarhoff, A.A. 1979. Care of the high risk neonate. Philadelphia: WB Saunders

16. Lynn, M.R. 1986. Determination and quantification of content validity. Nursing Research, 35 (6), November/December, 382-385.

17. Moore, M.L. 1972. The newborn and the nurse. Philadelphia: WB Saunders.

18. Perez, R.H. 1981. Protocols for perinatal nursing practice. Toronto: CV Mosby.

19. Roberton, N.R.C. 1983. A manual of neonatal intensive care. London: Edward Arnold Publishers.
20. Vestall, K.W., McKenzie, S.A.M. 1983. High risk perinatal nursing. Philadelphia: WB Saunders.

21. Wylde, H.C., Partridge, E.H. 1978. Webster universal dictionary. Holland: NV Uitgeversmaatschappij.

\section{Erkennings}

1. Die Suid-Afrikaanse Verpleegstersvereniging vir die toekenning van 'n Florence Nightingale beurs.

2. Die Randse Afrikaanse Universiteit, Departement Verpleegkunde se navorsingseenheid vir finansiële bystand.

Hierdie artikel is gebaseer op navorsing wat vir die graad M.CUR. (Verloskunde) aan die Randse Afrikaanse Universiteit gedurende 1988 onderneem is.

Johanna C. Roux, M.Cur. (Verloskunde) $R A U$, Morningside kliniek Verpleegkundige

Marie E. Muller, M.A.(Cur.), UNISA Randse Afrikaanse Universiteil Senior Lektrise (Verplegingsbestuur) Anna G.W. Nolte, D. Litt et Phil., UNISA Randse Afrikaanse Universiteit Mede Professor (Verloskunde) 